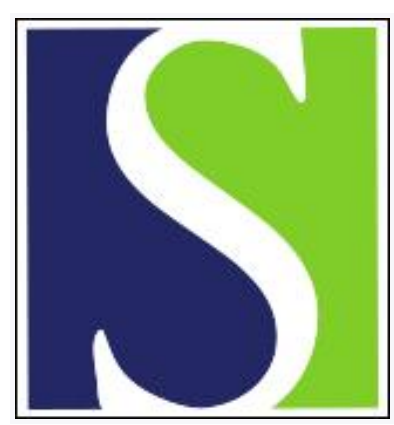

Scand J Work Environ Health 1983;9(1):9-14

https://doi.org/10.5271/sjweh.2441

Issue date: Feb 1983

Lung function of sheet metal workers exposed to fiber glass.

by Sixt R, Bake B, Abrahamsson G, Thiringer G

This article in PubMed: www.ncbi.nlm.nih.gov/pubmed/6857190






\title{
Lung function of sheet metal workers exposed to fiber glass
}

\author{
by Rune Sixt, MD, ${ }^{1}$ Björn Bake, MD, ${ }^{1}$ Gunnar Abrahamsson, MD, ${ }^{2}$ \\ Gunnar Thiringer, $\mathrm{MD}^{3}$
}

\begin{abstract}
SIXT R, BAKE B, ABRAHAMSSON G, THIRINGER G. Lung function of sheet metal workers exposed to fiber glass. Scand $j$ work environ health 9 (1983) $9-14$. Out of 532 registered and contacted sheet metal workers, 251 responded, but only seven pairs were acceptable for the present study due to the following requirement: no history of smoking, pleural plaques or asbestos exposure. Seven of these workers were exposed daily to fiber glass, and seven were almost never exposed. In a second step nine additional exposed workers were included. Ordinary spirometry, lung volumes, closing volumes and the slope of the alveolar plateau, the maximum expiratory flow in air and after heliumoxygen breathing, and the elastic recoil pressures were measured. No evidence of small airway dysfunction or restrictive or obstructive ventilatory impairment was found, but the elastic recoil pressures of the exposed group were slightly increased. Fiber glass can conceivably cause a corresponding faint and probably harmless fibrous reaction in the lung parenchyma.
\end{abstract}

Key terms: density dependence, elastic recoil pressure, flow-volume curves, single-breath nitrogen test.

Fiber glass has been commercially available for more than 40 years. The increased awareness of the harmful effects of asbestos - ie, fibrosis of the lung parenchyma and, in recent years, also its cancerogenicity - has focused interest on the possible injurious effects of fiber glass. Occasional cases have been reported in which this material has been pointed out as the possible harmful agent $(2,11,14)$. The causal association has been uncertain however.

Several epidemiologic studies based on the radiographic examination of the lungs of workers heavily exposed to fiber glass have failed to show an increased preva-

1 Department of Clinical Physiology, University of Göteborg, Göteborg, Sweden.

2 The Construction Industries Organisation for Working and Environment Safety and Health, Göteborg, Sweden.

3 Department of Occupational Medicine, University of Göteborg, Göteborg, Sweden.

Reprint requests to: Dr B Bake, Department of Clinical Physiology, Sahlgrenska sjukhuset, S-413 45 Göteborg, Sweden. lence of pathological findings $(15,24)$. Studies of lung function have also failed to reveal any chronic effects of fiber glass inhalation $(3,10,22)$.

The development of new lung function tests, more sensitive than earlier methods in revealing subtle changes in the small peripheral airways, made further studies on workers exposed to fiber glass of interest, particularly since, according to some of these tests, apparently healthy asbestosexposed subjects (9) and welders (18) have been shown to be affected. The object of the present study was to determine whether these new tests could reveal changes in subjects exposed to fiber glass.

\section{Subjects}

The basic population of the study comprised sheet metal workers from the Göteborg area. These workers fell into two welldefined categories: one often exposed to fiber glass and one never or seldom ex- 
Table 1. Selection of the subjects.

\begin{tabular}{lc}
\hline & $\begin{array}{c}\text { Number of } \\
\text { workers }\end{array}$ \\
\cline { 2 - 2 } Distributed questionnaires & 532 \\
Completed questionnaires & 251 \\
Smoking habits & \\
Smokers & 120 \\
Exsmokers & 66 \\
Nonsmokers & 65 \\
Fiber glass exposure & 50 \\
$\quad$ Exposed nonsmokers & 15 \\
$\quad$ Nonexposed nonsmokers & \\
\hline
\end{tabular}

posed. The study was confined to life-long nonsmokers.

By means of a questionnaire - distributed through the trade union - we obtained 65 nonsmoking subjects (table 1), 15 of whom had never been exposed to fiber glass and could therefore be used as referents for comparison with 15 exposed subjects. The exposed subjects and referents were pair-matched for age $( \pm 4$ a) and height $( \pm 4 \mathrm{~cm})$.

Six of the 15 subjects in the exposed group had been exposed to asbestos for more than three months. Two of them had pleural plaques, and one had pleural plaques and parenchymal changes consistent with asbestosis. In the reference group, pleural plaques were found in 5 out of 15 subjects, but none had been exposed to asbestos. Consequently, because of exposure to asbestos for more than three months and/or pleural plaques, we excluded seven pairs of subjects from further analysis. Yet another pair was excluded because the referent (not exposed to asbestos) had a history of repeated pleuritic illness. The final analysis thus comprised seven exposed subjects and seven matched referents. The mean values (range) of the age, height, and accumulated time of fiber glass exposure of the groups are given in table 2 .

\section{Methods}

A rolling-seal servospirometer with electric output for volume and flow was used to obtain an ordinary spirogram [vital ca- pacity (VC), forced expiratory volume in $\left.1 \mathrm{~s}\left(\mathrm{FEV}_{1}\right)\right]$ and flow-volume curves (maximum expiratory flows when $50 \%$ and $25 \%$ of the VC remained in the lung $\left[\mathrm{MEF}_{50}\right.$ and $\mathrm{MEF}_{25}$, respectively)]. The increase in the corresponding flows, ie, $\triangle \mathrm{MEF}_{50}$, $\triangle \mathrm{MEF}_{25}$, determined by [( $\left.\mathrm{MEF}_{\mathrm{He}}-\mathrm{MEF}_{\mathrm{air}}\right) /$ $\mathrm{MEF}_{\text {air }} \cdot 100$, was calculated after three $\mathrm{VC}$ inhalations of a helium-oxygen mixture (80/20) (4). Closing volume, the slope of the alveolar plateau, and the amplitude of the cardiogenic oscillations were assessed by the nitrogen technique (16). Total lung capacity (TLC) was measured with a body plethysmograph (5). The static elastic recoil pressure of the lung at different lung volumes (\%'CLC) was assessed by the esophageal balloon technique (12). The volume and pressure signals were calibrated at each measurement. The group mean values of the lung function variables have been expressed as the percentage of the predicted level.

The exposure to fiber glass has been given as accumulated exposure (eg, 3 months/year for 10 years $=30$ months). It was not possible to estimate the fiber content in the air.

The paired t-test has been applied to test the difference between the group means.

\section{Results}

In the exposed group, two subjects claimed cough in the morning and sputum production during the day in the wintertime. In connection with exposure to fiber glass, three subjects noticed cough and phlegm, two cough only, and one subject cough and dyspnea. In the reference group two subjects claimed to wheeze when having a cold.

The group mean values for TLC, VC, and $\mathrm{FEV}_{1}$ are given in table 3 . No individual showed values below $80 \%$ of the predicted level. The group differences were small and nonsignificant.

Table 4 summarizes the results of the nitrogen test and the flow-volume curves. The group means for the closing volume and the slope of the alveolar plateau were not significantly different. The mean amplitudes of the cardiogenic oscillation were similar for the groups. Furthermore, no single subject - whether exposed or not 
Table 2. Physical characteristics and estimated accumulated exposure to fiber glass - Mean values and ranges.

\begin{tabular}{|c|c|c|c|c|c|c|}
\hline & \multicolumn{2}{|c|}{$\begin{array}{c}\text { Age } \\
\text { (years) }\end{array}$} & \multicolumn{2}{|c|}{$\begin{array}{l}\text { Height } \\
\text { (cm) }\end{array}$} & \multicolumn{2}{|c|}{$\begin{array}{c}\text { Accumulated fiber } \\
\text { glass exposure } \\
\text { (years) }\end{array}$} \\
\hline & Mean & Range & Mean & Range & Mean & Range \\
\hline $\begin{array}{l}\text { Exposed group }(\mathrm{N}=7) \\
\text { Reference group }(\mathrm{N}=7)\end{array}$ & $\begin{array}{l}32.1 \\
31.6\end{array}$ & $\begin{array}{l}27-36 \\
23-40\end{array}$ & $\begin{array}{l}177.6 \\
175.9\end{array}$ & $\begin{array}{l}168-183 \\
166-183\end{array}$ & $\begin{array}{l}1.9 \\
-\end{array}$ & $\begin{array}{c}1-2.5 \\
-\end{array}$ \\
\hline
\end{tabular}

Table 3. Spirometric results for the exposed subjects (nonsmokers) and the matched referents - Mean values and the standard errors (SE) of the means. a

\begin{tabular}{|c|c|c|c|c|c|c|}
\hline & \multicolumn{2}{|c|}{$\begin{array}{l}\text { Total lung capacity } \\
\text { (\% of predicted) }\end{array}$} & \multicolumn{2}{|c|}{$\begin{array}{l}\text { Vital capacity } \\
\text { (\% of predicted) }\end{array}$} & \multicolumn{2}{|c|}{$\begin{array}{l}\text { Forced expiratory } \\
\text { volume in } 1 \mathrm{~s} \\
\text { (\% of predicted) }\end{array}$} \\
\hline & Mean & $\mathrm{SE}$ & Mean & SE & Mean & SE \\
\hline $\begin{array}{l}\text { Exposed group }(\mathrm{N}=7) \\
\text { Reference group }(\mathrm{N}=7)\end{array}$ & $\begin{array}{c}96.2 \\
96.1 \\
\text { NS }\end{array}$ & $\begin{array}{l}2.0 \\
1.9\end{array}$ & $\begin{array}{c}105.1 \\
103.7 \\
\text { NS }\end{array}$ & $\begin{array}{l}3.3 \\
1.7\end{array}$ & $\begin{array}{l}98.0 \\
95.3 \\
\text { NS }\end{array}$ & $\begin{array}{l}3.1 \\
2.7\end{array}$ \\
\hline
\end{tabular}

a Predicted normal vital capacity and forced expiratory volume in $1 \mathrm{~s}$ according to Berglund et al (1) and total lung capacity according to Grimby \& Söderholm (6). NS $=p>0.05$ (paired t-test).

Table 4. Results of the single-breath nitrogen test, maximal expiratory flows, and the change in the exposed subjects (all nonsmokers) and in the referents (all nonsmokers) following helium-oxygen breathing - Mean values and the standard errors (SE) of the means. ${ }^{a}$ (CV = closing volume; VC = vital capacity; $\Delta N_{2}=$ slope of the alveolar plateau; $N_{2}$ osc = amplitude of the cardiogenic oscillations; $M E F_{50} \& M F_{25}=$ maximum expiratory flow when 50 and $25 \%$, respectively, of the $V C$ remains in the lung; $\triangle M E F_{50} \& \Delta M E F_{25}=$ increase in $M E F_{50} \& M E F_{25}$, respectively; \% pred = percentage of the predicted value).

\begin{tabular}{|c|c|c|c|c|c|c|c|c|c|c|c|c|c|c|}
\hline & \multicolumn{2}{|c|}{$\begin{array}{c}\text { CV (\%VC) } \\
\text { (\% pred) }\end{array}$} & \multicolumn{2}{|c|}{$\begin{array}{c}\Delta N_{2} \\
(\% \text { pred) }\end{array}$} & \multicolumn{2}{|c|}{$\begin{array}{ll}\mathrm{N}_{2} & \text { OSC } \\
(\% & \left.\mathrm{N}_{2}\right)\end{array}$} & \multicolumn{2}{|c|}{$\begin{array}{l}M^{M E F_{50}} \\
(\% \text { pred })\end{array}$} & \multicolumn{2}{|c|}{$\underset{(\%)}{\triangle M E F_{50}}$} & \multicolumn{2}{|c|}{$\begin{array}{l}\mathrm{MEF}_{25} \\
\text { (\% pred) }\end{array}$} & \multicolumn{2}{|c|}{$\underset{(\%)}{\Delta M_{25}}$} \\
\hline & Mean & $\mathrm{SE}$ & Mean & SE & Mean & $\mathrm{SE}$ & Mean & $\mathrm{SE}$ & Mean & $\mathrm{SE}$ & Mean & SE & Mean & SE \\
\hline $\begin{array}{l}\text { Exposed group }(\mathrm{N}=7) \\
\text { Reference group }(\mathrm{N}=7)\end{array}$ & $\begin{array}{c}93.5 \\
94.5 \\
\text { NS }\end{array}$ & $\begin{array}{l}5.5 \\
8.9\end{array}$ & $\begin{array}{r}85.9 \\
101.1 \\
\text { NS }\end{array}$ & $\begin{array}{l}11.3 \\
12.9\end{array}$ & $\begin{array}{c}0.80 \\
0.74 \\
\text { NS }\end{array}$ & $\begin{array}{l}0.15 \\
0.15\end{array}$ & $\begin{array}{c}86.3 \\
74.4 \\
\text { NS }\end{array}$ & $\begin{array}{l}6.2 \\
4.7\end{array}$ & $\begin{array}{c}40.3 \\
42.3 \\
\text { NS }\end{array}$ & $\begin{array}{l}4.0 \\
7.9\end{array}$ & $\begin{array}{c}81.7 \\
73.3 \\
\text { NS }\end{array}$ & $\begin{array}{r}10.3 \\
6.8\end{array}$ & $\begin{array}{c}23.1 \\
25.9 \\
\text { NS }\end{array}$ & $\begin{array}{l}3.8 \\
7.9\end{array}$ \\
\hline
\end{tabular}

Table 5. Elastic recoil pressure at various lung volumes (\%TLC) for the exposed subjects (all nonsmokers) and for the referents (all nonsmokers) - Mean values and standard errors of the means, expressed as the percentage of the predicted normal. (Pel = static elastic recoil pressure)

\begin{tabular}{|c|c|c|c|c|c|c|c|c|c|c|}
\hline & \multicolumn{2}{|c|}{ Pel 60} & \multicolumn{2}{|c|}{ Pel 70} & \multicolumn{2}{|c|}{ Pel 80} & \multicolumn{2}{|c|}{ Pel 90} & \multicolumn{2}{|c|}{ Pel 100} \\
\hline & Mean & SE & Mean & SE & Mean & SE & Mean & SE & Mean & SE \\
\hline Exposed group $(\mathrm{N}=6)$ & 123 & 7.1 & 122 & 5.9 & 121 & 5.2 & 120 & 5.6 & 117 & 8.6 \\
\hline $\begin{array}{l}\text { Reference group } \\
(N=6)\end{array}$ & $\begin{array}{c}96 \\
\text { NS }\end{array}$ & 5.1 & $\begin{array}{r}96 \\
p<0\end{array}$ & $\begin{array}{l}4.0 \\
05\end{array}$ & $p<0$ & 02 & $\begin{array}{l}100 \\
p<0\end{array}$ & $\begin{array}{l}2.7 \\
02\end{array}$ & $\begin{array}{l}102 \\
\text { NS }\end{array}$ & 5.1 \\
\hline
\end{tabular}

a Predicted values according to our own prediction based on results from 30 healthy nonsmoking males $23-72$ years of age. NS = difference between the groups not significant $(p>0.05$, paired $t$-test $)$. 
- exhibited an abnormally high closing volume or slope of the alveolar plateau. The group mean value of the $M E F_{50}$ was slightly lower for the referents, but the difference was not significant $(p>0.1$, table 4). The response to helium-oxygen breathing did not separate the exposed group from the referents. One subject in the reference group had a $\triangle \mathrm{MEF}_{50}$ of less than $20 \%$, ie, there was evidence of density independence (4). The elastic recoil pressure was consistently higher in the exposed group in comparison to the reference group. The difference was significant at lung volumes between 70 and $90 \%$ of the TLC (table 5).

\section{Discussion}

The inclusion of smokers may be expected to reduce the possibility of revealing the discrete effects of occupational exposure on lung function (18). We therefore decided to use only nonsmoking subjects, who constituted approximately $25 \%$ of the total male population available for study. In order to obtain a sufficiently large number of subjects for study, all sheet metal workers in the Göteborg area who were members of the trade union were contacted ( $\mathrm{N}=522)$. As is obvious from table 1 , the response rate was very low $(47 \%)$, in spite of our cooperation with the trade union and two additional contacts. We can only speculate about the factors guiding the individual in his decision of whether or not to participate and about the extent to which this large primary dropout influences the general applicability of the findings. One of the consequences of the low response rate and our decision to study only nonsmokers was that the number of presumptive referents was limited to 15 .

The group available for analysis was further reduced as a number of subjects had to be excluded because of exposure to asbestos - which has a potential effect on lung function that almost certainly outweighs the potential effect of fiber glass (3). These considerations highlight two problems inherent in every study on occupational hazards, ie, the need for a very large basic population and the difficulty in ascertaining pure exposure.

It seems that symptoms involving the respiratory tract - unrelated to occupa- tional exposure - were equally common in both our groups. On the other hand, irritation of the upper airways during heavy exposure has been reported (13), and in our exposed group six out of seven subjects claimed cough when exposed. This result may indicate that, periodically, there is a high number of airborne fibers with an aerodynamic diameter associated with deposition in the larger airways. The net time of exposure may seem rather short (table 2), but it corresponds to occupational handling of fiber glass for 6 to 10 years.

Our study gives no spirometric evidence of the development of restrictive ventilatory impairment, a result which is in line with that of previous reports $(3,10)$. In earlier studies the nitrogen test has revealed tobacco-induced changes in smokers without symptoms (18) and changes presumably located in the small peripheral airways or the lung parenchyma in nonsmoking welders (17). In the present study, however, the nitrogen test did not reveal significant differences between subjects exposed to fiber glass and referents, and we were thus unable to demonstrate any effect of fiber glass on the small peripheral airways. The flow-volume curves gave results to the same effect. If anything, it seems that the reference group deviated more from the predicted values than the exposed group did. Furthermore, the similarity in the $\triangle \mathrm{MEF}_{50}$ and $\triangle \mathrm{MEF}_{25}$ of our groups indicates that the distribution of the central and peripheral airway resistance was equal, which also appears to contradict the possibility of adverse effects of fiber glass.

While neither the nitrogen test nor the flow-volume curves separated the subjects exposed to fiber glass from the referents, we did find a significant difference in the elastic properties of the lung, with slightly but consistently higher recoil pressure in the exposed group. No single subject exhibited an abnormally high recoil pressure however. The interpretation of this small difference is uncertain. Fibrosis of the parenchyma would tend to increase elastic recoil - as is the case in asbestosis and silicosis - whereas obstructive disease may instead be associated with lowered elastic recoil. A fundamental question is then whether the difference between the pressure-volume relationships should be 
taken to indicate increased elastic recoil in the exposed group or a corresponding decrease in the referents.

In comparison to our laboratory standard, it certainly appears as if the exposed group deviates towards high elastic recoil (table 5). The same impression prevaiis when the exposed group is compared with generally accepted reference material (21), although such a comparison is inherently uncertain due to possible differences in the populations and methodology.

When, in an attempt to verify our findings, we extended our study by another nine exposed subjects (nonsmokers, mean age 44.2 years, mean net exposure 3.2 years) who were not investigated initially because there were no appropriate referents, the exposed group did not deviate significantly from the reference group in respect to elastic recoil pressure at any lung volume. Including all exposed subjects, we did, however, still find a shift to the right of the pressure-volume curve (fig 1 ), which is significant at a lung volume of 60,70 and $80 \%$ of the TLC.

Is this slightly elevated recoil pressure indicative of a fibrotic process in the lung parenchyma of subjects exposed to fibrous glass? Alveolar deposition is favored when the fiber diameter is less than $3 \mu$ and the length is shorter than $200 \mu(8,20)$. In addition, the fibrinogenic effect is reported to be increased when the fiber length is above $10 \mu$ (19). Indoor measurements of airborne fibers at places of work indicate that the majority of glass fibers are less than $3 \mu$ in diameter and between 10 and $200 \mu$ in length. Therefore the possibility cannot be excluded that fiber glass can elicit a fibrous reaction in the lung parenchyma. Asbestos fibers, which are known to cause fibrosis of the lung, fulfill the size requirements for alveolar deposition, but the concentration of respirable asbestos fibers is probably much higher (7) and therefore more hazardous.

On the other hand, it must be realized that selection mechanisms are already in play in the choice of occupation, and it may be totally unwarranted to infer that small deviations of subgroups (eg, occupational categories) from a reference mean are caused by pathological processes.

Even if the increase in elastic recoil found in the exposed group is in fact caused by fiber glass exposure, the prog-

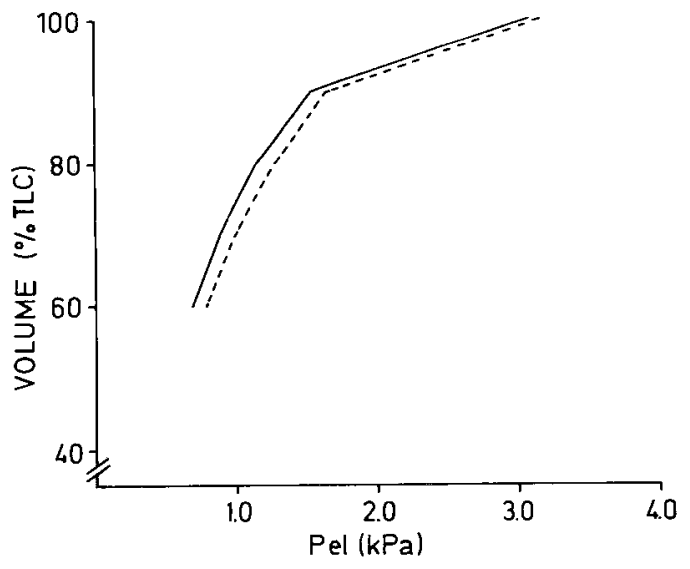

Fig 1. Mean pressure-volume curve for the extended group of subjects exposed to fiber glass (broken line) in relation to a reference curve (solid line). (Pel = static elastic recoil pressure).

nosis nevertheless appears favorable since epidemiologic studies have failed to reveal an increased mortality or incidence of lung disease among subjects exposed to fiber glass $(22,24)$.

In summary, in a small number of subjects exposed to fiber glass, we found slightly increased elastic recoil but no evidence of small airway dysfunction, restrictive ventilatory impairment, or airway obstruction. It is not possible from this study to generalize as to the hazard of handling fiber glass, but it may serve to indicate a need for further studies on the effect of fiber glass inhalation on lung function.

\section{Acknowledgment}

The present study was supported by grants from the Construction Industries Organisation for Working and Environment Safety and Health and the Swedish $\mathrm{Na}$ tional Association against Heart and Chest Diseases.

\section{References}

1. Berglund E, Birath G, Bjure J, Grimby G, Kjellmer I, Sandqvist L, Söderholm B. Spirometric studies in normal subjects: I Forced expirograms in subjects between 7 and 70 years of age. Acta med scand 173 (1963) 185-191.

2. Bezjak B. Damage to the lung caused by glass wool. Arch hig rada toksikol 7 (1957) $338-343$. 
3. Bjure J, Söderholm B, Widimsky J. Cardiopulmonary function studies in workers dealing with asbestos and glass wool. Thorax 19 (1964) 22-27.

4. Despas PJ, Leroux M, Macklem PT. Site of airway obstruction in asthma as determined by measuring maximal expiratory flow breathing air and helium-oxygen mixture. $\mathrm{J}$ clin invest 51 (1972) 3235-3243.

5. DuBois AB, Bothelho SY, Bedell G, Marshall R, Comroe JH Jr. A rapid plethysmographic method for measuring thoracic gas volume: A comparison with a nitrogen wash-out method for measuring functional residual capacity in normal subjects. $J$ clin invest 35 (1956) $322-326$.

6. Grimby G, Söderholm B. Spirometric studies in normal subjects: III Static lung volumes and maximum voluntary ventilation in adults with a note on physical fitness. Acta med scand 173 (1963) 199-206.

7. Gross P, Harley RA, Davis JMG. The lungs in fiber glass workers: A comparison with the lungs of a control population. I Occupational exposure to fibrous glass. US Government Printing Office, Washington, DC 1976, pp 249-263. (HEW publication no (NIOSH) 76-151).

8. Harris RL Jr. Aerodynamic considerations: What is a respirable fiber of fibrous glass? I Occupational exposure to fibrous glass. US Government Printing Office, Washington, DC 1976, pp 51-56. (HEW publication no (NIOSH) 76-151).

9. Hedenstierna B, Alexandersson R, Kolmodin-Hedman B, Szamosi A, Tollqvist J. Pleural plaques and lung function in construction workers exposed to asbestos. Eur j respir dis 62 (1981) 111-122.

10. Hill JW, Whitehead WS, Cameron JD, Hedgecock GA. Glass fibres: Absence of pulmonary hazard in production workers. $\mathrm{Br} \mathrm{j}$ ind med 30 (1973) $174-179$.

11. Kahlau G. Tödliche Pneumonie nach Glasstaubinhalation durch Verarbeitung eines Kunsstoffes aus Glaswolle. Frankfurter Z Pathol 59 (1947) 143-150.

12. Milic-Emili J, Mead J, Turner JM, Glauser EM. Improved technique for estimating pleural pressure from eosophageal balloons. J appl physiol 19 (1964) 207-211.

13. Mungo A. Processing pathology of the stratified compounds with glass wool base Folia med 43 (1960) 962-970.

14. Murphy GB Jr. Fiber glass pneumoconiosis. Arch environ health 3 (1961) 704710.

15. Nasr AN, Ditchek T, Scholtens PA. The prevalence of radiographic abnormalities in the chests of fiber glass workers: I Occupational exposure to fibrous glass. US Government Printing Office, Washington, DC 1976, pp 225-235. (HEW publication no (NIOSH) $76-151$ ).

16. Oxhöj H, Bake B. Measurement of closing volume with the single breath nitrogen method. Scand j resp dis 55 (1974) 320-331.

17. Oxhöj $H$, Bake $B$, Wedel $H$, Wilhelmsen $L$. Effects of electric arc welding on ventilatory lung function. Arch environ health 34 (1979) $211-217$.

18. Oxhöj H, Bake B, Wilhelmsen L. Ability of spirometry, flow-volume curves and the nitrogen closing volume test to detect smokers: A population study. Scand $\mathrm{j}$ resp dis 58 (1977) $58-80$.

19. Stanton MF, Layard M, Tegeris A, Miller M, May M, Kent E. Carcinogenicity of fibrous glass: Pleural response in the rat in relation to fiber dimension. $\mathrm{J}$ natl cancer inst 58 (1977) $587-603$.

20. Timbrell V. The inhalation of fibrous dusts. Ann ny acad sci 132 (1965) 255-273.

21. Turner JM, Mead J, Wohl ME. Elasticity of human lungs in relation to age. $\mathrm{J}$ appl physiol 25 (1968) 664-671.

22. Utidjian M, Cooper WC. Human epidemiologic studies with emphasis on chronic pulmonary effects: I Occupational exposure to fibrous glass. US Government Printing Office, Washington, DC 1976, pp 193-197. (HEW publication no (NIOSH) $76-151)$.

23. Wilhelmsen L. Lung mechanics in rheumatic valvular disease. Acta med scand suppl 489 (1968) 1-114.

24. Wright $\mathrm{CW}$. Airborne fibrous glass particles: Chest roentgenograms in persons with prolonged exposure. Arch environ health 16 (1968) 175-181.

Received for publication 17 September 1982 